\title{
A AFLITIVA INSISTENECIA: pensamento crítico cultural e teoria das bordas
}

Frederico Fernandes (UEL)

Em seu discurso "A auto-afirmação da universidade alemâ"1, Martin Heidegger lança as bases para um projeto acadêmico-nacionalista assentado na produçáo do saber como condutor do espírito nacional. Para ele, a ciência encontra-se intrinsecamente ligada à produção variável e contínua do saber, situando-se no terreno da práxis. Com isso, ele contrapóe-se à recorrente ideia de que teoria e prática constituem-se como atividades dissociadas e opostas, ao descrevê-las como em engrenagens de um mecanismo mecanismo.

De tal perspectiva, o saber revela-se como uma atitude teórica (Heidegger, 2007, p.156). "Teoria", no sentido da Antiguidade grega que Heidegger a resgata, significa "estar em obra", ou seja, ela é entendida como a mais alta realização prática. Não é demais acrescentar que a acepção latina de "teoria" que a toma como "esquema mental e formulação de conceito" não se encontra desatrelada da palavra grega theoros - que era o espectador das arenas de jogos e de teatro. Teoria forma-se por thea, "vista", acrescida de horan, "olhar". Nas palavras de Heidegger, a teoria é a "pura contemplação", realiza-se "na paixão de ficar junto ao ente enquanto tal e na sua aflitiva insistência". (2007, p. 157) Destaco a expressão: "aflitiva insistência". Seu disposto apresenta uma enorme semelhança com o que Blaise Pascal (1623-1662) escreveu em seus Pensamentos a respeito da produção do saber. De acordo com Pascal: "a doença principal do homem é 
a curiosidade inquieta das coisas que não pode saber" (1988, p.41-42). A prerrogativa heideggeriana da aflição corresponde, também, à inquietante condição do pesquisador diante de seu tema de investigação. Trata-se de uma aflição comparada à inquietaçáo do escritor de frente para a página em branco, na busca da palavra por meio da qual arquitetará o mundo possível literário. Para o pesquisador/teórico, o exercício de conexão de seu espírito à matéria exterior não produz uma aflição de menor intensidade.

Esse fluxo filosófico inspira a pensar a obra de Jerusa Pires Ferreira e sua aflitiva insistência em desvendar os mecanismos de produção e circulação dos textos orais e impressos populares. Seu processo de construção teórica afina-se, ao longo de mais de 4 décadas de carreira acadêmica, com a denominação de "bordas".

Não é o copioso volume de artigos e livros publicados ao longo de sua trajetória como docente junto à USP e PUC/SP. Não são os 94 mestres e doutores citados em seu currículo que estenderam e ramificaram seus ensinamentos. Não se trata do ofício da tradutora de Zumthor, Meschonic, Stendhal. Nem é o trabalho institucional caracterizado pelo seu papel na fundação do Grupo de Trabalho de Literatura Oral e Popular da ANPOLL, do Centro de Estudos da Oralidade da PUC, da sua colaboração junto ao Núcleo de Ciências da Comunicação junto à Universidade Metodista de Sáo Paulo e, também, de várias revistas. Trata-se da sua aflitiva insistência em lidar com um tema e suas ramificaçóes. Trata-se de questionar um paradigma, penetrar os trincos da crítica consolidada, reorganizar as tarefas e insistir na abertura do diálogo. Instar a matéria até que ela lhe revele outros sentidos, outras possibilidades de compreensão do mundo. Jerusa ocupa-se de fidelizar-se à paixão de sua contemplação, até que dela advenha ideias que expliquem os mecanismos da dúvida e lhe possibilitem lançar-se à teorização.

Não há nenhum exagero em dizer que Jerusa é uma intelectual rebelde, como muitos de sua geração (Tom Zé, Wally Salomão, Haroldo de Campos, Glauber Rocha, Raul Seixas e muitos outros). Assim como ela, são em sua maioria baianos (e notem que se o autor dos versos de "Circuladô de fulô" não é baiano de nascimento o é de espírito!).

Rebeldia aqui não deve se confundir com desrespeito e teimosia, sinônimos encontrados nos dicionários. A rebeldia intelectual consiste numa forma saudável e necessária de questionamento, sem que para isso a tradiçáo seja equivocadamente alçada à condição de inimiga. A rebeldia intelectual pressupóe o diálogo, criando uma fissura espaciotemporal em que a lógica linear dá lugar à conjunção sincrética de expressóes de diversas temporalidades. A rebeldia intelectual se realiza pelo exercício da paralaxe, num questionamento sobre a relatividade do centro.

O famoso poema visual de Hélio Oiticica em homenagem ao bandido Cara de Cavalo, executado brutalmente pelo esquadrão da morte, em que ele afirma "seja mar- 
ginal, seja herói”, é aqui apropriado para alçar à síntese do que entendo como a prática da rebeldia acadêmica: "seja questionador, olhe para/com as margens".

Mas em que sentido a palavra "questionar" está sendo apreendida, já que se trata de um verbo poliédrico que tanto quer dizer "disputar", "discutir", como, em sua grandiosidade, pode significar atender a chamado do mundo? Mais uma vez, Heidegger faz-se necessário para depurar o sentido do questionar. Escreveu ele:

O questionar não é mais então apenas o estágio preliminar superável à resposta enquanto saber, mas o questionar torna-se ele próprio a mais alta figura [Gestalt] do saber. O questionar desenvolve então sua mais própria força de descerramento do essencial de todas as coisas. O questionar compele então à mais extrema simplificação do olhar lançado sobre o que é incontornável. (2007, p.158)

Ser dotado de uma sensibilidade-pélago, o intelectual rebelde é aquele incumbido de guiar o espírito para a incessante incerteza do mundo. Ele precisa da energia da ativa teoria, pois por meio da contemplação, iluminará os caminhos para atenuar a aflição, transcender a dúvida, superar a curiosidade. Mas ao aceitar os novos trânsitos que se abrem pela teoria, o pesquisador se vê num outro terreno onde as incertezas voltarão a minar.

E vale um parênteses para enfatizar que a diferença entre a incerteza e a ignorância é muito acentuada. A ignorância repousa no ser, projetando-o para a incapacidade de envolvimento, de sensibilização, de tomada de consciência e, consequentemente, de construção de saber. A ignorância o conduz para a estática e contida aceitaçáo de fenômenos e coisas do mundo.

A incerteza, por sua vez, não prescinde do trânsito. A dúvida e a curiosidade podem levar a erros e acertos, mas certamente ocasionam um movimento: o do questionamento. A incerteza é regida pelo contínuo de um mundo em observação e traz em seu devir o estágio inicial da inovação. Assim, a ignorância preme e imobiliza. A incerteza reclama a resposta. Por isso, o incerto chama o ser para a teoria, para o conhecimento derivado da observação do mundo. É assim na academia, mas também são assim os benzedeiros, rezadeiras e muitas profissões artesanais que extraem seu conhecimento da observação da natureza, estabelecendo com ela uma ordem lógica.

A incerteza de Jerusa a levou a constituir um campo específico de estudos (seu porto seguro?) que ela denominou "cultura das bordas". Trata-se de um campo teórico, onde os recorrentes trânsitos culturais impulsionam o pesquisador dos textos orais e impressos para o movimento contínuo das incertezas. Em seu livro, de 2010, que não por acaso possui como título Cultura das bordas, ela a define como [e eu cito] "aquela que 
não é a cultura oficial; é trazida e recriada por indivíduos que participam desse mesmo continuum de visão de mundo e repertório, com diversas gradaçóes”. Este livro compóe-se de 3 partes, totalizando 10 capítulos, e tem como subtítulo "edição, comunicação, leitura”, delimitando o escopo de suas investigaçóes e análises. No campo das bordas, ocorre "a recuperação de linguagens em depósito, de saberes enraizados no universo popular, há uma força de resistência que não se pode negar e que até se transforma em não resistência e acomodação social, em conservadorismo político”. (2010, p. 93).

Trata-se de uma cultura contígua à grande indústria de massas, não se definindo plenamente com o folk, mas mantendo com ele evidentes relaçóes de trocas. A cultura das bordas dirige-se a públicos moventes nas grandes cidades, tem no espaço urbano contemporâneo o entroncamento privilegiado de temporalidades, modos de vida e campos de interesse variados. Ela se baseia numa espécie de "metaconhecimento", termo caro a Paul Zumthor e muito bem incorporado por Jerusa desde suas incursóes iniciais em 1979, com Cavalaria de Cordel, que baseia-se em conhecimentos prévios, arraigados na memória popular. Por isso, grimórios como o livro de São Cipriano (abro um outro parênteses para dizer que este livro também foi tema de um estudo de Jerusa publicado em 1992, ganhador do prêmio Jabuti de melhor ensaio), as adaptaçóes de clássicos (como Fausto, Divina Comédia, Eneida), histórias baseadas em fatos reais de criminosos ou de personagens populares como Lampião, do revolucionário nicaraguense Augusto Sandino, almanaques, enfim, brochuras que adotam diagramação e cromatismo da capa em tons singulares, estratégias claras de disseminação é que vão compor o mosaico de textos da cultura das bordas.

A trajetória de Jerusa tem demonstrado que a voz, um dos mais fortes fios condutores de sua carreira, encontra-se em muitos momentos entrelaçada com a letra e, náo raras vezes, são originários da mesma estriga. Há nisso uma percepção diferenciada a respeito do texto em relação ao meio em que circula, algo muito semelhante ao que Jurij Lotman postula a respeito do lubok (estampas populares caracterizadas por desenhos e narrativas, que se apresentam tanto como objeto de decoração como livros).

Paga a pena a citação de um trecho do ensaio La natura artística dele stampe poplari russe, na tradução italiana de Luciana Guidici, em que Lotman observa [e eu faço aqui a tradução da tradução]:

o mundo do folclore na arte requer do público um posicionamento muito particular. No âmbito da cultura escrita o público 'consome' o texto (escuta ou lê, o retém). Na atmosfera da cultura folclórica, o público joga com o texto e para o texto. Para entender que coisa quero dizer é útil recordar o fato que muitos conhecem bem por já ter visto pessoalmente e que é também descrito pela pedagogia: o modo como as crianças vivem as 
'imagens'. As crianças não retêm, mas observam o material ilustrado, o tocam e o giram e, se o texto lhes toca, começam a saltar, gritar e cantar. (2009: p.86) ${ }^{2}$

O olhar sensível do semiólogo russo transcende o suporte que analisa, percebendo nele uma relação de jogo e a reação extática denunciada pelo corpo e pelo grito. Tal sensibilidade também é encontrada nos escritos de Jerusa, seja ao perceber as reaçóes de seus editores entrevistados ou no olhar sensível e penetrante dispensado ao fenômeno. No capítulo "Memória, magia e tramoia", de seu Cultura das Bordas, a pesquisadora brasileira afirma:

Será preciso ver tudo o que esta literatura conglomerada, tantas vezes falaciosa, inscreve no escrito; tudo o que ela inflete para o útil, para a prática. Se ela não é uma literatura apenas de tradição oral, não deixa de o ser; leitura e escritura são necessárias para incorporação de um lastro, muito antigo, bem engastado e, em certo sentido, até revolucionário. Bastou lembrar, por exemplo, a Inquisição e perseguiçóes sofridas, e o que torna específico, decididamente uno, este universo que, certo ou errado para nós, é aquele que pertence a grande número de pessoas e que enriquece o nosso de formas e concepçôes muito próprias, permanecendo no universo dos públicos populares ainda hoje. (2010, p. 99-100).

O trânsito é, sem dúvida, a principal prerrogativa para a definição das bordas, uma vez que elas se apresentam como uma "Faixa de transição entre uns e outros" (Idem, p.30), cuja abrangência atinge públicos populares de várias tribos e periferias, sendo composta por textos que transitam entre culturas ditas "populares e das 'elites" (Idem, p. 34). Em meio a tal dinâmica, jogos de ideias, fluxos e refluxos de narrativas, personagens e acontecimentos, que vão ressignificar o imaginário e projetar a fantasia por um matiz luzente, está o pesquisador se questionando e insistindo na compreensão dos fatos. Mais do que a sensibilidade engenhosa, estão os passos dados pelo teórico. No caso de Jerusa, tais passos a levam da condição de pesquisadora para o terreno do popular, sem que sua trajetória de vida seja neutralizada no percurso. Isso pode ser notado pela recorrência da primeira pessoa em sua narrativa, e cito algumas passagens:

Eu já sabia, a partir das informaçôes difusas e através de um de seus editores [...] (p.22) Abro aqui um parêntese para contar que meu avô, que tinha uma farmácia e um pequeno laboratório de produtos médicos [...] editava o Almanaque Agrário que circulava no Sertão da Bahia, com relativo sucesso. (p. 40)

Meu pai, Celso de Carvalho (1901-1986), sempre falou desse livro contando que seu padrinho, o vigário Cupertino de Lacerda, grande orador sacro da Bahia, não dispensava e que também o via frequentemente em mãos de leigos. (p.63) 
Aqui veste como uma luva a discussão de Roland Barthes (1987), publicada em $O$ rumor da língua, a respeito do emprego da terceira pessoa corrente no texto acadêmico, por meio da qual o cientista faz sua autoexclusão psicológica, passional e biográfica. ${ }^{3}$ Jerusa segue no oposto e por quê? Porque as bordas em toda sua energia transitória, em seus movimentos, implicam um ponto de referência: a thea grega daquele que olha. O movimento é quase idêntico ao de João Cabral de Melo Neto pelas ruas de Sevilha, tão bem retratado em $A$ educaçáo pela pedra, no qual público e o privado formam, na geometria de seu pensamento, duas faces de uma mesma moeda. Refiro-me ao poema "A urbanizaçáo do regaço", do qual cito os seguintes versos:

Os bairros mais antigos de Sevilha

Criaram uma urbanização do regaço

Para quem, em meio a qualquer praça,

Sente o olho de alguém a espioná-lo,

Para quem sente nu no meio da sala

E se veste com os cantos retirados. [...]

Eles têm o aconchego que a um corpo

Dá estar noutro, interno ou aninhado,

Para quem torce a avenida devassada

E enfia o embainhamento de um atalho,

Para quem quer, quando fora de casa,

Seus dentros e resguardo de quarto. (1994, p.359)

O estranhamento inicial sobre as vias de Sevilha, daquele que se sente nu no meio da sala, vai sendo invadido pela sensação de aconchego, do regaço que acolhe o poeta e o torna familiar às ruas. A vida privada confunde-se com a pública, sem que para isso uma soleira tenha que ser transpassada, uma vez que fora de casa o poeta encontra seus "dentros" e toda sua intimidade. A ocupação de espaços públicos num país como o Brasil tem se tornado cada vez mais desafiadora por conta das diferenças sociais (produto e causa da violência sem limites). Nas cidades, em seus bairros de classe média alta com muralhas comadas por cercas elétricas dos grandes condomínios, que mais lembram presídios de alta segurança, bem como a interdição de espaços públicos em determinados horários em alguns bairros periféricos são cada vez mais comuns. As cidades fomentam uma arquitetura da exclusão que faz lembrar os cercos no entorno de vilarejos medievais construídos para frear as hordas em seu ímpeto de violência e saque. Um projeto acadêmico-nacional nos dias de hoje requer do pesquisador a disponibilidade para ir ao encontro de tais grupos que se isolam, fortalecendo o espírito das 
trocas e, mais, criando uma unidade em que as diferenças são o motor de sua contínua construção. Individualizar-se, restringir, impor limites: o polo oposto da cultura das bordas.

Jerusa, enquanto intelectual, transita pelas periferias brasileiras a la Cabral de Melo Neto sobre as ruas da Sevilha antiga. A lembrança do pai e do avô marca uma presença: o dentro da casa para o espaço público, em que a intimidade torna-se a forma mais sincera de apresentação do estudo. Isto é sem dúvida o grande ensinamento de Jerusa enquanto pesquisadora ao colaborar com a condução do espírito acadêmico: o de que o intérprete-teórico inevitavelmente habita as palavras dos textos que produz, mostrando a falácia do esconso ao pesquisador de terceira pessoa.

A prática teórica torna-se, em tal perspectiva, uma atitude de exposição: exposição de si, mas também de "todos os poderes mundanos da existência histórica", como já afirmava Heidegger, em seu discurso citado. Mais do que uma sistematização da pesquisa, as confluências e as congruências, os nós e os deslocamentos, os rearranjos e as permanências de um tema demonstram que o pesquisador lida com mapas em seu porvir.

É fato que o conceito de cultura das bordas vai se assemelhar a outros tantos criados no pensamento crítico cultural das últimas 3 décadas. Nesse sentido, a aproximação com as culturas híbridas de Néstor Garcia Canclini torna-se inevitável, pois ambos, com enfoques diferenciados, chegam a reflexôes aproximadas. Dois aspectos se ressaltam na formação do pensamento crítico cultural com base nas culturas híbridas e na cultura das bordas: a) o entendimento de que o espaço urbano não se evidencia como o antípoda do mundo rural, tornando um locus de interseção e confluências culturais; e b) o de que as formas de comunicação produzidas neste espaço serão responsáveis por alterar a dinâmica público privado.

Desse modo, a cultura híbrida e a cultura das bordas não renunciam à cidade como o cenário onde as práticas culturais vão sendo gestadas e transformadas. Muito pelo contrário, as cidades em seus aglomerados urbanos e centros periféricos demandam expressar e se manifestam em modos particulares. A sociedade tem assistido a uma profusão de artes que tendem a se enquadrar nos mais variados epítetos: periféricas, subalternas, marginais, de minorias, populares, entre outras. Elas são, em síntese, o resultado do contingenciamento espacial da expressão poética de um sujeito que se repensa e pensa o espaço público de convivência em meio às transformaçôes das relaçóes sociais operadas com a expansão do mundo urbano. Os diários de Carolina Maria de Jesus, o sertão já citadino de um Patativa do Assaré, o rap de Mano Brown e dos Racionais MC's, o compositor Criolo, o teatro hip-hop de Roberta Estrela D'Alva, as histórias dos sapatinhos mágicos de Efigênia Rolim no Largo da Ordem em Curitiba, a folia de Reis 
de seu Garbosi na periferia de Londrina, a viola de cocho e o cururu do mestre Agripino de Corumbá, os poemas encadernados em espiral de Maragato no bairro da Restinga em Porto Alegre, são alguns exemplos da arte que rompe os limites e as fronteiras de seus mundos, ganhando, em alguns casos, a atenção da grande mídia e da academia.

Os grupos sociais, em suas nucleaçóes periféricas, conectam-se por meio de poetas, artesãos, músicos, atores, dançarinos, grafiteiros, em suma, sujeitos que protagonizam um papel artístico, tanto no anonimato ou no reconhecimento de seus pares. Como afirma Canclini:

A urbanização predominante nas sociedades contemporâneas se entrelaça com a serialização e o anonimato na produção, com reestruturaçôes da comunicação imaterial (dos meios massivos à telemática) que modificam os vínculos entre o privado e o público. Como explicar que muitas mudanças de pensamento e gostos da vida urbana coincidam com os do meio rural, se não por que as interaçóes comerciais deste com as cidades e a recepção da mídia eletrônica nas casas rurais os conecta diretamente com as inovaçóes modernas? (1998, p. 285-286)

O espaço urbano é apreendido pela contemplação de práticas culturais que nele transitam. É a "pura contemplação" no espírito em que a postulou Heidegger. Desse modo, a interpretação do espaço urbano requer do intelectual o posicionamento insistente daquele que levanta questionamentos sobre os trânsitos. Ele não é imune às investidas políticas e é compelido a pensar a emancipação humana, reconhecendo na arte um dos meios legítimos pelo qual o coletivo vai se expressar. A práxis intelectual não o leva a ser confundido com um intelectual pragmático, isto é, à disposição da atividade de gerenciamento de grupos. Pelo contrário, sua prática consiste em "ficar junto ao ente enquanto tal", isto é, perscrutando-o, refletindo sobre a ordem dos acontecimentos, arquitetando formas de intervenção, lutando contra sua redução à invisibilidade e à utilização da linguagem como mecanismo de aprisionamento do sujeito ao consumo. Por isso, também, a crítica cultural contemporânea requer um intérprete que alça as fronteiras mais avançadas da tecnologia comunicacional e do conhecimento por ela mediado.

Devido à transformação contínua (e acelerada), o espaço urbano trona-se, também, o campo das incertezas. Não se trata de um conhecimento elaborado, da academia para o grupo social, mas de um acadêmico que o produz durante sua investigação e atuação junto aos grupos que pesquisa. A universidade, assim, se fortalece com a incursão do acadêmico nas ruas, pois é no contato com a incertezas que a teoria deriva. $\mathrm{O}$ espírito condutor e, ao mesmo tempo, (re)formulador da teoria encontra sua plenitude na pró- 
pria dinâmica que o engendra. Tal força não é outra senão o seu necessário continuum, o que traz também para o pesquisador a alegria de sua existência.

De uma perspectiva etimológica, o sujeito aflito é aquele que se encontra sob o jugo do flagelo. $\mathrm{O}$ antigo chicote romano, flagellum, do qual se origina a palavra aflição, é um objeto cuja finalidade é causar dor e desconforto. Assim, o acadêmico só pode se encontrar diante de um flagelo metafórico, cuja saída é outra senão a via que neutralizará sua condição aflitiva, com o objetivo de atingir a alegria. Combustível necessário do ânimo, a alegria motiva o trabalho e gera confiança na ação. A nota final de Cultura das Bordas, com a qual também encerro este artigo, não deixa dúvidas sobre o fim último do trabalho de pesquisa, estágio posterior ao da aflitiva insistência do intelectual contemporâneo:

Há aí uma certa alegria da descoberta em atividades de pesquisa, nas grandes bibliotecas do mundo e também nas ruas, em incursões pelas cidades de São Paulo e do Rio de Janeiro. Foi construída uma espécie de 'etnologia' urbana itinerante, definindo e ampliando lugares e razóes de conhecimento, e apontando para novas práticas de ler e de compreender. (Ferreira, 2010, p. 155)

\section{$\operatorname{son}$}

\section{NOTAS}

1 Discurso pronunciado pela ocasião da polêmica nomeação de Heidegger como reitor Universidade de Freiburg durante o regime nazista, em 27 de maio de 1933. Esta nomeação lhe rendeu a acusação de ter colaborando com o regime de Hitler, a qual não se sustentou em sua trajetória de vida.

2 No original: “ Il mondo del floclore nell'arte attribuisce al pubblico uma posizione del tutto particolare. Nell'ambito dela cultura scritta il pubblico 'consuma' il texto (escolta o legge, guarda). Nell atmosfera dela cultura folclórica il pubblico gioca com il texto e al texto. Per capire cosa intendiamo dire è utile ricordare um fato che molti conoscono bene per averlo osservato personalmente e che è comunque descrito nella letteratura pedagógica: il modo in cui i bambini vivono le 'immagini'. I bambini non 'guardano', ma osservano il materiale ilustrato, lo toccano e lo girano e, se il texto li há colpiti, comincianno a saltare, gridare o cantare.”.

3 Reproduzo o que já escrevi em $A$ voz e o sentido sobre a impessoalidade no discurso acadêmico, baseado em Roland Barthes: "Na construção de uma análise, o pesquisador busca 'limpar' os elementos que denunciam a interação do eu com o outro, o que desencadeia um processo de 'auto-exclusão'. Roland Barthes entende que esta exclusão nunca ocorre no plano do 'sujeito', restando ao cientista excluir apenas sua pessoa (psicológica, passional, biográfica). Ou seja, o preenchimento do texto necessita de alguém que o faça (um sujeito) e, sendo assim, a objetividade plena no discurso 'é um imaginário como qualquer outro' (Barthes, 1987, p. 16). O fato é que o discurso da ciência é regido por uma verdade impessoal e o cientista se respalda num discurso assimilado e lapidado ao longo da história da ciência. Por isso, escrever em primeira 
pessoa poderia soar demasiadamente empírico, ao passo que o 'se' reflexivo permitiria este suposto distanciamento em relação ao objeto. No caso da pesquisa com outros seres humanos, isto constitui uma espécie de teatralização, na qual a postura do pesquisador se bifurca: em campo, corresponde a uma interação com o entrevistado; no processo de escrita, à eliminação de vestígios denunciadores dessa relação." (Fernandes, 2007, p. 160-161)

\section{REFERÊNCIAS}

BARTHES, Roland. O rumor da língua. Trad. Antônio Gonçalves. Lisboa: Ediçóes 70, 1987.

CANCLINI, Néstor Garcia. Culturas Híbridas: estratégias para entrar e sair da modernidade. Trad. Ana R. Lessa e Heloísa P. Cintrão. São Paulo: Edusp, 1998.

FERNANDES, Frederico. $A$ voz e o sentido. Poesia Oral em Sincronia. São Paulo: Editora Unesp, 2007. FERREIRA, Jerusa Pires. A cultura das bordas. Edição, comunicação, leitura. São Paulo: Ateliê Editorial, 2010.

Cavalaria em cordel: o passo das águas mortas. 2 ed. São Paulo: Hucitec, 1993.

Armadilhas da memória: conto e poesia popular. Salvador: Fundaçáo Casa de Jorge Amado, 1991.

HEIDEGGER, Martin. A auto-afirmação da universidade alemã. In: Terceira Margem. Revista do Programa de Pós-Graduação em Ciência da Literatura. Trad. Daniel Pucciarelli. Rio de Janeiro. Ano XI, n. 17, jul/dez. 2007.

LOTMAN, Jurij M. La natura artística dele stampe poplari russe. Trad. e org. Luciana Guidici. Miláo: Book Time, 2009.

MELO NETO, João Cabral. A educação pela pedra. In: Obra Completa. Rio de Janeiro: Nova Aguilar, 1994.

PASCAL. Blaise. Pensamentos. Tras. Sérgio Milliet. 4. Ed. São Paulo: Nova Cultural, 1988. (Coleção Os Pensadores).

\section{Resumo}

Este artigo trata da obra de Jerusa Pires Ferreira e está focado em sua ideia de "cultura da borda". Baseado no livro homônimo, Cultura das Bordas, o artigo discute a relação entre o acadêmico e seu campo de pesquisa. Alguns aspectos fazem-se evidentes, por exemplo: a teoria diz respeito a um tipo de trabalho prático especial, o acadêmico lida com a incertezaq diante dos fatos a serem analisados; o conhecimento corresponde a um porvir, de modo a manter uma profunda conexão e intimidade com o grupo estudado.

\section{Abstract}

This article is focused on Jerusa Pires Ferreira's idea of "culture of border". Based on her Cultura das Bordas book, this article deals with the relationship between the scholar and his/her field of research. Some aspects become evident, for example, the theory concerns a kind of special practical work; the scholar deals with uncertainty in front of facts to be analysed; the knowledge corresponds to a work-in-progress in a way of maintaining a deep connection and an intimacy with the group studied. 
Frederico Fernandes é professor associado do Departamento de Letras Vernáculas e Clássicas da UEL. Mestre e doutor em Letras, possui pós-doutorado junto à Brock University (Canadá, 2008-2009) e Università di Bologna (20014-2015). Autor de vários livros e coletâneas sobre as relaçóes entre poesia, voz e oralidade. Entre alguns de seus títulos merece ser destacado $A$ voz e o sentido (Edunesp, 2007) e As razóes da Voz (Eduel, 2014). Coordena atualmente o Portal de Poéticas Orais: www.portaldepoeticasorais.com.br 